\title{
Spallation of reinforced concrete slabs under contact explosion
}

\author{
Jun Li \\ School of Civil, Environmental and Mining Engineering \\ The University of Adelaide \\ Adelaide, Australia \\ Chengqing $W u$ \\ School of Civil and Environmental Engineering \\ University of Technology Sydney \\ Sydney, Australia
}

\author{
Hong Hao \\ Department of Civil Engineering, \\ Curtin University \\ Perth, Australia.
}

\begin{abstract}
Structures and their occupants are imposed to great threat under blast loading environment. The current design and research practices mainly focus on structural responses and damages under far field or close-in detonations. The blast scenarios involving contact explosions are not extensively investigated. Under contact explosions, highly localized damage caused by severe stress wave propagation is commonly seen, and this damage mode is significantly different from other dynamic loading types in which structural members usually respond in flexural or shear mode. In recent decades, the necessity of gaining in-depth knowledge about this extreme loading event is highlighted as threat from terrorism activities is rising. In the present study, contact test results on reinforced concrete members are presented. Performances of slabs made of normal strength concrete and steel wire mesh reinforced concrete are compared and discussed.
\end{abstract}

Keywords—steel wire mesh; slabs; contact explosions

\section{INTRODUCTION}

Structural response under dynamic loading condition is a topic of increasing interest in recent decades. Short duration high intensity loads like impact or blast may excite local response of a structure. The damages observed on post-blast structural components are usually flexural shear or direct shear damages [1] in which their design loading capacity is not fully developed. Given there is no sufficient structural redundancy, damage of individual component can cause the disproportional collapse of the entire structure [2] that is now an important concern for structural engineers and researchers.

To provide a rational protective design of structures against accidental or hostile explosions, it is critical to understand the blast loads magnitudes and their distributions on the structures. The magnitude and distribution of air blast loads is a function of the type of explosive material, weight and shape of the explosive, distance and location of the explosive relative to the structure, and the interaction of the shock front with the ground and the target structure. Until now, most information about air blast loads is empirical and the most extensively used blast load parameters (including blast overpressure and impulse) are plotted versus the scaled blast standoff distance (R/W1/3) as presented in manual UFC 3-340-02 [3]. It is worth noting that when it comes to the explosions in close proximity to or even in contact with the structure, since the loadings of these scenarios are extremely severe and complex, it is very difficult to conduct an accurate measurement, and the curves in UFC manual therefore start at about $\mathrm{R} / \mathrm{W}^{1 / 3}=0.2 \mathrm{ft} / \mathrm{lb}^{1 / 3}(0.08$ $\left.\mathrm{m} / \mathrm{kg}^{1 / 3}\right)$.

In case contact explosions occur, structural components usually suffer highly localized damage such like concrete crush and spall, and these damages are induced by stress wave propagation rather than global deformation. Upon detonation, high intensity compressive stress wave impinges on the concrete surface which easily exceeds the dynamic compressive strength and induces concrete crush. When blast induced compressive stress wave strikes the free surface of concrete in which it propagates, it will reflect and turns into tensile stress wave. At a certain depth of the concrete, if the resultant stress is larger than dynamic concrete tensile strength, concrete spall initiates. Stress wave changes shape and magnitude as they propagate through the concrete, and these changes are dependent on wave attenuation, divergence, and dispersion. In general sense, concrete spall is dependent on material strength, porosity, reinforcement spacing and other imperfections while it is relatively insensitive to structural boundary conditions.

Analytical solutions to stress wave induced concrete material failure are complex. Existing trials are based on simplifications which overlook the influence of wave attenuation and dispersion. Furthermore, these methods are based on assumption that blast load can be determined in a specified scenario, however, as mentioned above, blast load prediction is extremely hard, if not impossible, to be obtained in a contact detonation case. Numerical simulation is useful tool for people to have better understanding on this phenomenon, and preliminary investigations have yielded some useful conclusions [4], [5] assessing residual loading capacity of concrete members after contact explosions.

To get well prepared for a protective design, ideally, concrete should be strong in both compression and tension. 
However, although it is relatively easy to achieve high compressive strength concrete (through changing the mix with lower water/binder ratio and high pozzolanic material addition such as silica fume), concrete tends to become more brittle when its compressive strength increases. Low tensile strength is main reason for concrete brittle damage including spallation, and efforts have been devoted to improving concrete tensile strength. An optimal amount of steel fibre addition has been proved to be effective providing micro confinement and bridging the crack so as to increase the concrete tensile capacity. Based on these two improvements, ultra-high performance concrete (UHPC) is formulated, and applications of UHPC against blast loads has been reported [6],[7].

In recent years, steel wire mesh (SWM) has been used to embed in concrete members for strengthening and rehabilitating purpose. As observed in an experimental work conducted by Dancygier and Yankelevsky [8], concrete with steel wire mesh reinforcement developed localized membrane effect when subjected to impact load and showed good scabbing resistance. El Debs and Naaman [9] studied bending behaviour of mortar reinforced with steel meshes and polymeric fibres, and they concluded that this combination can satisfy the ultimate strength limit state through the steel mesh reinforcement (main reinforcement) and to control cracking under service loads through fibre reinforcement (secondary reinforcement). Although SWM reinforcement technology showed some good potentials in structural engineering, the study of utilizing it against blast load especially contact explosions is not found in the literature review.

To gain more knowledge of SWM reinforced concrete, in the present study, two concrete slabs, one made of normal strength concrete (NSC) with steel bar reinforcement, and the other one made of high strength concrete (HSC) with steel wire mesh reinforcement are field tested under contact explosions. The latter slab is further protected by adding steel fibre material into the concrete covers to confine the scabbing and spalling.

\section{SAMPLE PREPARATION AND TEST PROGRAM}

As shown in Figure 1, the dimension of slabs is: $2000 \mathrm{~mm}$ long, $800 \mathrm{~mm}$ wide and $120 \mathrm{~mm}$ thick. The diameters of the longitudinal reinforcing rebar and stirrup rebar are $12 \mathrm{~mm}$ and $10 \mathrm{~mm}$, respectively. Both of these two reinforcements are designed with $360 \mathrm{MPa}$ yielding strength.

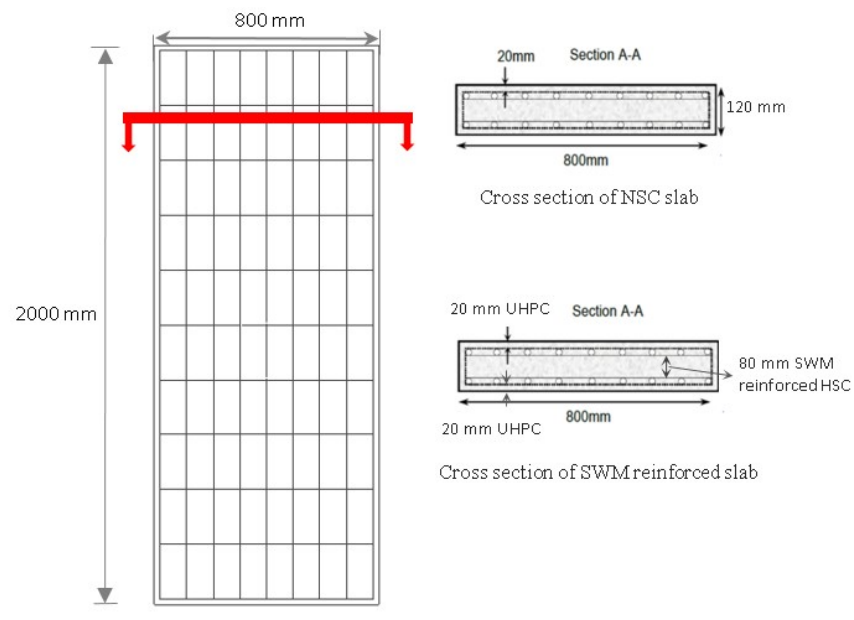

Fig. 1. Dimension and reinforcement of slabs in contact explosion test

NSC slab was constructed by concrete with nominal unconfined compressive strength of $40 \mathrm{MPa}$. SWM slab was constructed by high strength concrete material with unconfined compressive strength of $75 \mathrm{MPa}$. After mixing 3\% weight dosage steel fibre material into the slab concrete covers, the cover concrete can be termed as ultra-high performance concrete (UHPC) with uniaxial compressive strength $145 \mathrm{MPa}$ and tensile strength $22 \mathrm{MPa}$. 30 layers of steel wire mesh with diameter of $1 \mathrm{~mm}$ and space of $6.35 \mathrm{~mm}$ was embedded in the slab between the concrete covers, the SWM was made of 304 stainless steel with a tensile strength of $500 \mathrm{MPa}$.

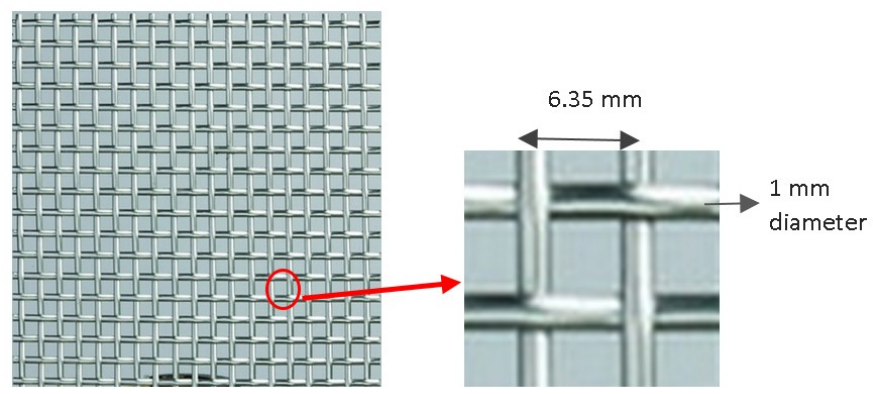

Fig. 2. Dimension of steel wire mesh

Testing apparatus and TNT explosive used in the contact explosion are shown in Figure 3. Bolting clamping system was used to stabilize the sab during the tests, it is believed that slab response under contact explosion is relatively insensitive to the boundary condition. 


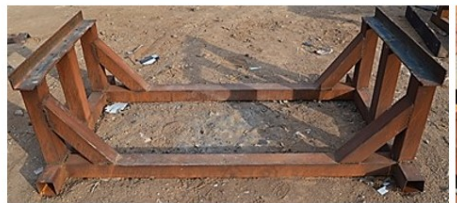

Steel support
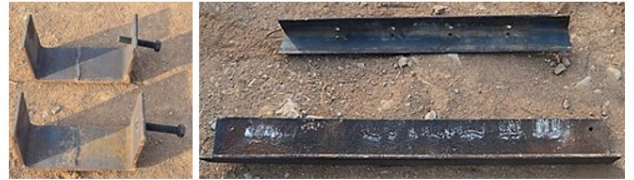

Bolts and steel cleats

Fig. 3. Supporting frame

\section{TEST RESULTS}

In blast event 1 , normal strength concrete slab was subjected to $1 \mathrm{~kg}$ TNT placing at the centre of slab surface. As can be noticed from Figure 4, severe blast load induced perforation failure in the slab. Fracture happened on the central stirrup reinforcement. It is also noted that significant concrete cracking occurred along the two unsupported directions near the slab boundary. As no obvious slab deformation was observed, these damages were believed also caused owing to stress wave propagation and reflection. Stress wave caused cracks along the two free ends because of the short propagation distance between the explosive and the free boundary, which generated large tensile stresses owing to wave reflection and hence scabbing failure of concrete.

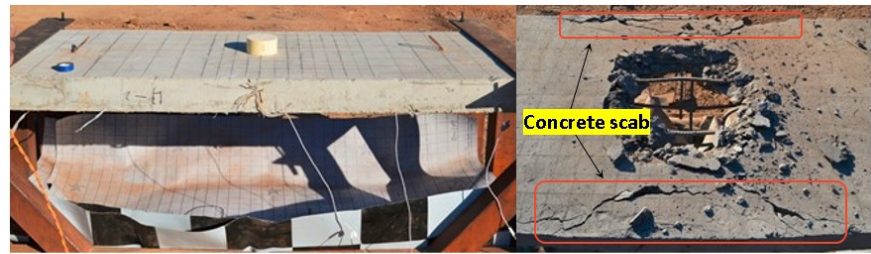

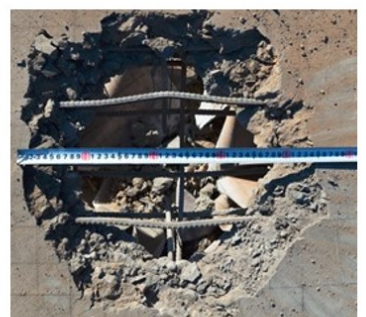

Top surface crater diameter $46 \mathrm{~cm}$

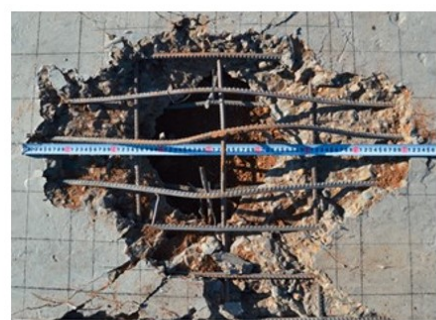

Bottom surface spall diameter $82 \mathrm{~cm}$
Fig. 4. Blast event 1 on NSC slab

In blast event 2, SWM slab was also subjected to $1 \mathrm{~kg}$ TNT placing at the centre of slab surface. As can be noticed from Figure 5, perforation failure in the slab was again observed. However, the perforation area was much confined when compared with normal strength slab $(15 \mathrm{~cm}$ diameter versus 30 $\mathrm{cm}$ diameter). This improvement can be explained in the following aspects. Firstly, during the wave propagation in the SWM slab, the close spacing steel wire meshes effectively dispersed the stress wave which in turn retarded wave propagation. Secondly, kinetic energy of particle movement was transferred to the elasticity and fracture energy of steel wire mesh and fracture of steel wire mesh absorbed large amount of energy which made the blast energy parsing through effectively reduced. Finally, when local large deformation occurred, the tensile membrane effect from multilayers of the steel wire mesh increases the scab and spall resistance. Side concrete spallation was noted which is similar to NSC slab, however, the spallation depth is reduced due to increased material tensile strength.

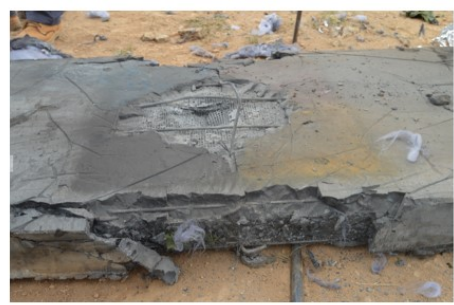

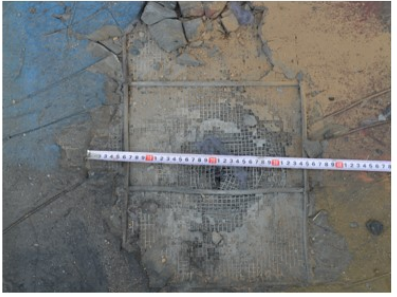

Top surface crater diameter $42 \mathrm{~cm}$

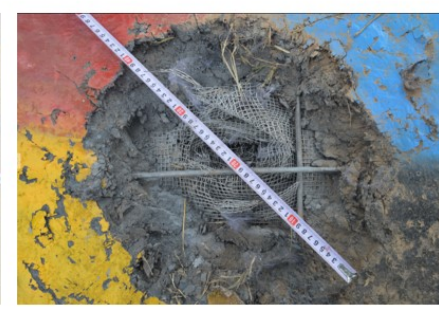

Bottom surface spall diameter $40 \mathrm{~cm}$
Fig. 5. Blast event 2 on SWM slab

\section{CONCLUSIONS AND DISCUSSIONS}

In the present study, regular strength and high strength concrete slabs with different types of reinforcement were subjected to the same contact explosions. Although high strength concrete contributes to the enhanced resistance of the slab against dynamic loads, it is prone to fail in a more brittle manner. Thus, if failure conditions occur, relatively larger craters will form, with larger fragments of concrete separated from the plate. To overcome these defects, steel wire mesh was used as reinforcement in high strength concrete slab and steel fibres were adopted at concrete cover layer to provide bridge effect once cracks initiated where strain reached peak value. In previous study, the effect of reinforcement in resisting the scabbing and spall was observed [8], however, it appears that the influence of the reinforcing bars depends also on their spacing, thus requiring, for the commonly used rebars diameters, a relatively heavy reinforcement ratio is required [5]. In the present study, instead of use large amount of steel rebar, steel wire mesh is used together with conventional rebar, the conventional rebar is used as primary resistance against conventional flexural load while steel wire mesh as an secondary reinforcement which can effectively disperse the blast wave generated in an explosion and provide better scab and spall resistance.

Key findings in the test confirmed the benefits of utilizing steel wire mesh against contact blast loads, comparing with NSC slab which suffered large area of perforation, SWM slab 
only had small area penetration and large amount of blast energy was dissipated through steel wire mesh fracture. The crater and spall dimeter of SWM slab were smaller than NSC slab. However, it is noted the side concrete spallation occurred in both NSC and SWM slabs which indicated a better design should be considered to reduce such kind of damage.

\section{ACKNOWLEDGEMENT}

The research presented in this paper supported by the ARC Discovery Grant DP140103025 is gratefully acknowledged.

\section{REFERENCES}

[1] J. Li, H. Hao, Influence of brittle shear damage on accuracy of the two-step method in prediction of structural response to blast loads, International Journal of Impact Engineering, 54 (2013) 217-231.

[2] J. Li, H. Hao, Numerical study of structural progressive collapse using substructure technique, Engineering Structures, 52 (2013) 101-113.

[3] US_Department_of_Defense, Structures to resist the effects of accidental explosions (UFC 3-340-02), in: Unified Facilities Criteria, Washington, DC, 2008.
[4] B. Li, A. Nair, Q. Kai, Residual axial capacity of reinforced concrete columns with simulated blast damage, Journal of Performance of Constructed Facilities, 26 (2012) 287-299.

[5] J. Li, H. Hao, Numerical study of concrete spall damage to blast loads, International Journal of Impact Engineering, 68 (2014) 41-55.

[6] J. Li, C. Wu, H. Hao, Investigation of ultra-high performance concrete slab and normal strength concrete slab under contact explosion, Engineering Structures, 102 (2015) 395-408.

[7] J. Li, C. Wu, H. Hao, An experimental and numerical study of reinforced ultra-high performance concrete slabs under blast loads, Materials \& Design, 82 (2015) 64-76.

[8] A. Dancygier, D. Yankelevsky, High strength concrete response to hard projectile impact, International Journal of Impact Engineering, 18 (1996) 583-599.

[9] M.K. El Debs, A.E. Naaman, Bending behavior of mortar reinforced with steel meshes and polymeric fibers, Cement and Concrete Composites, 17 (1995) 327-338. 